\title{
Sodium Butyrate Upregulates miR-203 Expression to Exert Anti-Proliferation Effect on Colorectal Cancer Cells
}

\author{
Ruirui Han ${ }^{\mathrm{a}}$ Qianqian Sun ${ }^{\mathrm{b}}$ Jianbo Wu ${ }^{\mathrm{b}}$ Pengyuan Zheng ${ }^{\mathrm{a}}$ Guoqiang Zhao ${ }^{\mathrm{b}}$ \\ aDepartment of Gastroenterology, the Fifth Affiliated Hospital of Zhengzhou University, Zhengzhou; \\ ${ }^{\text {bS }}$ chool of Basic Medical Sciences, Zhengzhou University, Zhengzhou, China
}

\section{Key Words}

Sodium butyrate $\cdot \operatorname{miR}-203 \cdot \operatorname{NEDD} 9 \cdot$ Colorectal cancer $\bullet$ Cell proliferation

\begin{abstract}
Background: As the end product of the bacterial fermentation of dietary fiber in the colonic lumen, sodium butyrate $(\mathrm{NaBt})$ has been reported to exert antitumor effects on colorectal cancer (CRC). In addition to functioning as a histone deacetylase (HDAC) inhibitor, NaBt also regulates the expression of microRNAs (miRNAs) to inhibit CRC cell proliferation. Yet, the mechanisms involved are not completely understood. Here we investigate whether $\mathrm{NaBt}$ regulates miR-203 to inhibit CRC growth and explore the promising target gene of miR-203 in CRC cells. Methods: We conducted qRT-PCR and Western blotting assays to evaluate the effects of NaBt on the expression of miR-203 and NEDD9 in HT-29 and Caco-2 cell lines. The promising target gene of miR-203 was predicted by miRNA target prediction and dual luciferase reporter assay. CRC Cell proliferation, colony formation, cell apoptosis and cell invasion assays were performed to explore the effect of NaBt, miR-203 and NEDD9 on HT29 and Caco-2 cell lines. Results: The results showed that NaBt increased the expression of miR-203 to induce CRC cell apoptosis as well as inhibit cell proliferation, colony formation and cell invasion. Moreover, we determined that the NEDD9 was a target gene of miR-203. NEDD9 partially overcame the inhibitory effects of miR-203 on CRC cell colony formation and invasion. Conclusions: NaBt could induce CRC cell apoptosis, inhibit CRC cell proliferation, colony formation and invasion through miR-203/NEDD9 cascade. The present study may enrich the mechanisms underlying the process that $\mathrm{NaBt}$ exerts anti-tumor effects on CRC cells.

\section{Introduction}

Colorectal cancer (CRC) is the third most common cancer and the fourth most common cause of cancer-related death in the world. More than 1.2 million patients are diagnosed with CRC, and more than 0.6 million patients die from the disease every year [1]. It is recognized that sodium butyrate $(\mathrm{NaBt})$, produced during fermentation of dietary fiber by anaerobic

R. Han and Q. Sun contributed equally to this work.

Pengyuan Zheng and Guoqiang Zhao

KARGER
Department of Gastroenterology, the Fifth Affiliated Hospital of Zhengzhou University, $3^{\#}$ Kangfu Front street, Zhengzhou 450052, Henan (China); School of Basic Medical Sciences, Zhengzhou University, Zhengzhou 450001, Henan, (China)

Tel./Fax+860371 66916927, E-Mail distantshore@163.com and zhaogq@zzu.edu.cn 
bacteria in the colon, exerts an anticancer effect on CRC [2-4]. However, the mechanisms have not been fully elucidated yet. Cumulative reports have confirmed that NaBt inhibits CRC as a histone deacetylase (HDAC) inhibitor, which can reactivate gene expression and inhibit the growth and survival of tumor cells [5-7].

On the other hand, it is reported that the ability of NaBt in the suppression of CRC cells is associated with its regulation of microRNA (miRNA), such as miR-106b family and miR17-92 cluster members expression [8-9]. miRNAs are small, non-coding RNAs that regulate the cellular pathways including cell cycle arrest, apoptosis, proliferation and differentiation [10-11]. More than 1000 miRNAs in human have been recognized, and most of them target hundreds of genes [12]. Genetic or epigenetic modifications alter the expression of miRNAs in various human tumors [13], and the dysregulation of miRNA expression is involved in carcinogenesis through regulating the expression of oncogenes or tumor suppressors [14]. In CRC cells, a lot of miRNAs have been found to affect cell growth, migration and invasion by regulating certain genes [15-18].

Published data indicate that miR-203 has the effects on inhibition of cell proliferation, cell invasion, cell metastasis, and the promotion of cell apoptosis [19-20]. In a previous study on skin tumor, miR-203 downregulation was shown to be prevented in presence of $\mathrm{NaBt}$, indicating that $\mathrm{NaBt}$ could exert its chemopreventive effects by modulating miR-203 levels in skin tumor [21].

Based on the above information, we hypothesize that NaBt can inhibit CRC by regulating miR-203 expression. In the present study, we observed the effects of $\mathrm{NaBt}$ on the expression of miR-203 in HT-29 and Caco-2 colorectal cell lines. Our data presented that NaBt upregulated miR-203 to restrict cell proliferation, colony formation, cell invasion, and induce cell apoptosis in CRC cells. Meanwhile, we determined NEDD9 as a target gene of miR-203, and NEDD9 partially reversed the inhibitory function of miR-203 upon CRC cell colony formation and invasion. These results may provide a novel miR-203/NEDD9 cascade in the process that $\mathrm{NaBt}$ exerts anti-proliferation effects on CRC cells.

\section{Materials and Methods}

\section{Cell culture}

HT-29 and Caco-2 cells (ATCC, Manassas, VA, USA) were cultured in RPMI 1640 medium (GIBCO Invitrogen $\mathrm{GmbH}$, Karlsruhe, Germany) containing 10\% fetal bovine serum (FBS) (BD Biosciences, San Dieo, CA, USA $)$ and antibiotics $\left(100,000 \mathrm{U} /\right.$ Lpenicillin and $100 \mathrm{mg} / \mathrm{L}$ streptomycin) at $37^{\circ} \mathrm{C}$ and $5 \% \mathrm{CO}_{2}$.

\section{Cell treatment and transfection}

For cell proliferation and colony formation assays, CRC cells of the NaBt group were treated with medium containing $4 \mathrm{mM}$ or $8 \mathrm{mM} \mathrm{NaBt}$ (Sigma, St. Louis, MO) in complete medium for the preset culture duration as hereinafter described [22]. For other studies, cells of the NaBt group were treated with $4 \mathrm{mM}$ or $8 \mathrm{mM}$ NaBt for 24 hours before experiment. Cell transfection was performed with Lipofectamine ${ }^{\mathrm{TM}} 2000$ (Invitrogen) following the manufacturer's instructions. HT-29 and Caco-2 cells seeded in 6-well plates were transfected with miR-203 mimics or scramble mimics at a concentration of $50 \mathrm{nM}$. The sequence of the miR-203 mimics is 5'-GUGAAAUGUUUAGGACCACUAG-3', 5'-AGUGGUCCUAAACAUUUCACUU-3'; the sequence of the scramble is 5'-UUCUCCGAACGUGUCACGUTT-3', 5'-ACGUGACACGUUCGGAGAATT-3'. NEDD9 was silenced by RNA interference with specific siRNA oligonucleotides. The target sequences genes were: 5'-UCCCAUGCAGGAGACUGC CUCCAGU-3'.

miRNA target prediction and dual luciferase reporter assay

miRNA target prediction was performed using bioinformatic algorithm TargetScan. To verify the prediction, a luciferase reporter assay was performed with the pmirGLO vectors (Promega Corporation, Madison, WI, USA) containing wild-type (WT) NEED9 3'-UTR and mutant-type (MT) NEDD9 3'-UTR. HT29 and Caco-2 cell lines were divided into four groups respectively. The first group was cotransfected with scramble mimics and pmirGLO-WT; the second group was cotransfected with miR-203 mimics and pmirGLO-WT; the third group was cotransfected with scramble mimics and pmirGLO-MT; and the fourth 


\section{Cellular Physiology Cell Physiol Biochem 2016;39:1919-1929

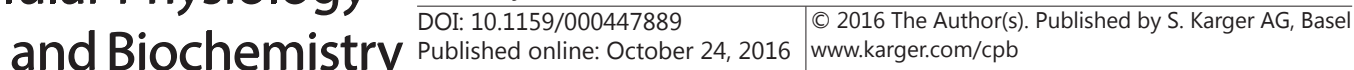 \\ Han et al.: Sodium Butyrate Inhibits Colorectal Cancer Cell Proliferation}

group was cotransfected with miR-203 mimics and pmirGLO-MT. Luciferase activities were measured with a Dual-Luciferase Reporter assay System (Promega).

Quantitative reverse transcription PCR ( $q R T-P C R)$

Total RNAs were extracted using Trizol reagent (Invitrogen) according to the manufacturer's instructions. All of the operations of the RNA were carried out under RNase-free conditions. RNA concentration was measured using a Biophotometer plus (Eppendorf, Hamburg, Germany) at $260 \mathrm{~nm}$, and the isolated RNA was stored at $-80^{\circ} \mathrm{C}$. $1 \mu \mathrm{g}$ of total RNA was used for reverse transcription to synthesize miRNA cDNA using gene-specific primers (Ribobio, Guangzhou, China) and the M-MLV RT kit (Invitrogen). miR-203 expression was assessed using qRT-PCR on the ABI PRISM 7500 Sequence Detection System. The fold changes in miRNA expression were determined using the $2^{-\Delta \Delta \mathrm{CT}}$ method, and the expression was normalized to the U6 small nuclear RNA expression level. The primers used for qRT-PCR of miR-203 were miR-203 forward 5'-GTGAAATGTTTAGGACCACTAGAA-3', U6 forward 5'-CGCTTCGGCAGCACATATAC-3', and the universal reverse primer 5'-GCGAGCACAGAATTA ATACGAC-3'. Each sample was analyzed in triplicate.

\section{Western blotting}

HT-29 and Caco-2 cells were lysed with RIPA buffer containing 1\% PMSF. Protein extracts were quantified using BCA kit (Beyotime, Haimen, China). Protein samples (50 $\mu$ g of each sample) were separated by SDS-PAGE and transferred onto PVDF membranes. After blocking with $5 \%$ skim milk for $1 \mathrm{~h}$, membranes were incubated with anti-NEDD9 antibodies (1:1,000) (Cell Signaling Technology, Danvers, MA, USA) or anti- $\beta$-actin antibodies (1:4,000) (Sigma-Aldrich, St. Louis, MO) overnight at $4{ }^{\circ} \mathrm{C}$. After washing by TBST, membranes were then incubated with HRP-conjugated secondary antibodies $(1: 10,000)$ (Santa Cruz Biotechnology, Santa Cruz, CA, USA). Finally, signals on the membranes were detected by enhanced chemiluminescence (Millipore, Billerica, MA, USA ) following the manufacturer's instructions.

\section{Cell proliferation and Colony formation assays}

Cell proliferation was evaluated with an MTT assay. CRC cells were plated in 96-well plates at $1 \times 10^{4}$ cells/well and incubated. Cell proliferation was assessed at 0, 24, 48, and $72 \mathrm{~h}$. In brief, $20 \mu \mathrm{L} \mathrm{MTT} \mathrm{(5mg/}$ $\mathrm{ml}$ ) was added to each well and incubated for $4 \mathrm{~h}$. The CRC cells were agitated with $150 \mu \mathrm{L}$ DMSO for 15 min. The absorbance at 490nm was recorded in the Epoch Microplate Spectrophotometer (Bio Tek, CA, USA). For colony formation assay, CRC cells were plated in 6-well plates at 200 cells/well and cultured for 14 days. Then the colonies were stained by $0.05 \%$ Crystal Violet solution for 1 hour. The number of colonies was assessed in four randomly selected fields.

\section{Cell apoptosis assay}

Cell apoptosis was assessed by flow cytometry (Beckman, USA). 24h after the cell transfection or treatment, the CRC cells were trypsinized and then processed with an Annexin V-FITC/PI Apoptosis Detection Kit (BD) according to the manufacturer's protocol. In brief, the CRC cells were washed with PBS and then resuspended in $200 \mu \mathrm{l}$ of binding buffer. $10 \mu \mathrm{l}$ Annexin V-FITC and PI were then added. Cells were incubated for10 minutes in the dark and then subjected to flow cytometry assay. Cells were gated and plotted for Annexin V-FITC and PI in a two way dot plot to assess the percentage of apoptotic CRC cells.

\section{Cell invasion assay}

Cell invasion was carried out in Transwell systems (Corning, USA). Transfected or treated CRC cells $\left(5 \times 10^{5}\right)$ were seeded in upper chambers coated with matrigel (BD) in serum-free medium. Medium with $20 \%$ FBS was filled in the lower champers. The non-invading cells were removed from the upper surface of the filter after $24 \mathrm{~h}$ incubation and the invading cells adhered to the bottom were fixed by $70 \%$ ethanol for $30 \mathrm{~min}$, stained by $0.2 \%$ crystal violet for $10 \mathrm{~min}$ and scored by counting five randomly selected fields per filter under a light microscope. All experiments were performed three times in triplicate.

\section{Statistical analysis}

Data are presented as mean \pm standard deviation (SD) from at least three independent experiments. Statistical analysis was conducted using SPSS 17.0. The differences between groups were assessed by Oneway analysis of variance (ANOVA). The differences were regarded significant when p-values $<0.05$. 


\section{Results}

NaBt upregulates miR-203 and downregulates NEDD9 in HT-29 and Caco-2 cells

To observe the correlations between NaBt and the levels of miR-203 or NEDD9 in CRC cells, we analyzed a qRT-PCR and a Western blotting assay separately. Compared with control group, miR-203 was significantly increased by NaBt in both HT-29 and Caco-2 cells $(\mathrm{P}<0.05$; Fig. 1a). There was no significant difference between the $4 \mathrm{mM}$ and $8 \mathrm{mM} \mathrm{NaBt}$ groups (P > 0.05; Fig. 1a). Western blotting showed that NaBt treatment reduced NEDD9 protein expression markedly in both HT-29 and Caco-2 cells (Fig. 1b and c).

\section{miR-203 directly targets NEDD9}

We performed a bioinformatic analysis to predict the target genes of miR-203. The results revealed that NEDD9 3'UTR had binding sites with hsa-miR-203, indicating that NEDD9 was a potential target of miR-203 (Fig. 2a). Western blotting revealed that miR-203 inhibited the NEDD9 protein expression in both HT-29 and Caco-2 cells (Fig. 2b and c). Dual luciferase reporter assays showed that transfection of the miR-203 mimics decreased the luciferase activity of the Wt NEDD9 reporter gene but not the Mt reporter gene in both HT-29 and Caco- 2 cells (Fig. $2 \mathrm{~d}$ and e). Taken together, the data above strongly indicate that NEDD 9 is the target gene of miR-203.

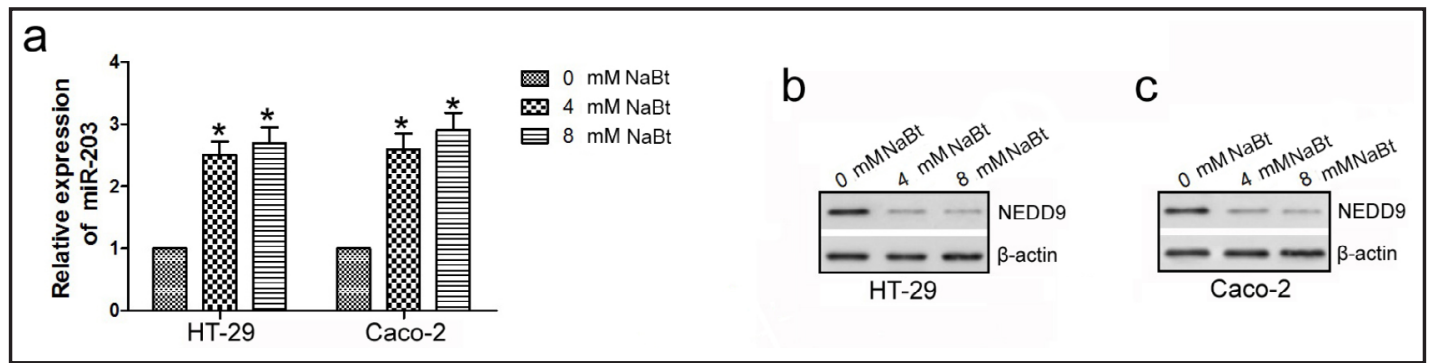

Fig. 1. NaBt upregulates miR-203 and downregulates NEDD9 in CRC cells. (a) qRT-PCR was used to evaluate relative expression of miR-203 in HT-29 and Caco-2 cells. Western blotting was conducted to analyze the levels of NEDD9 protein in HT-29 (b) and Caco-2 cells (c). ${ }^{*} P<0.05$, compared with the control group. Error bars represent \pm S.E.

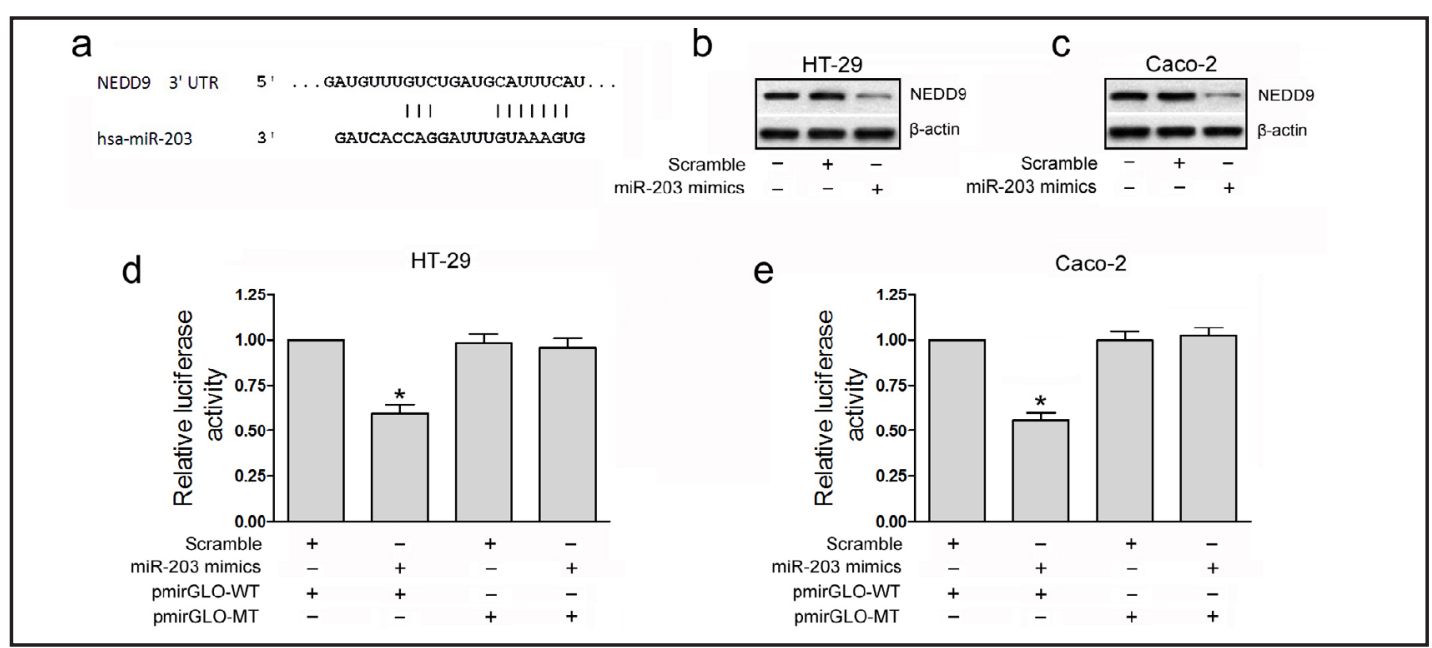

Fig. 2. miR-203 directly targets NEDD9. (a) Sequence alignment of miR-203 and NEDD9 3'-UTR was analyzed by bioinformatic analysis. Western blotting showed the levels of NEDD9 in HT-29 cells (b) and Caco-2 cells (c). ß-actin was applied as a control for the examination of NEDD9. Luciferase reporter assay revealed the luciferase activity of HT-29 (d) and Caco- 2 cells (e). ${ }^{*} P<0.05$, compared with the scramble groups. Error bars represent \pm S.E. 


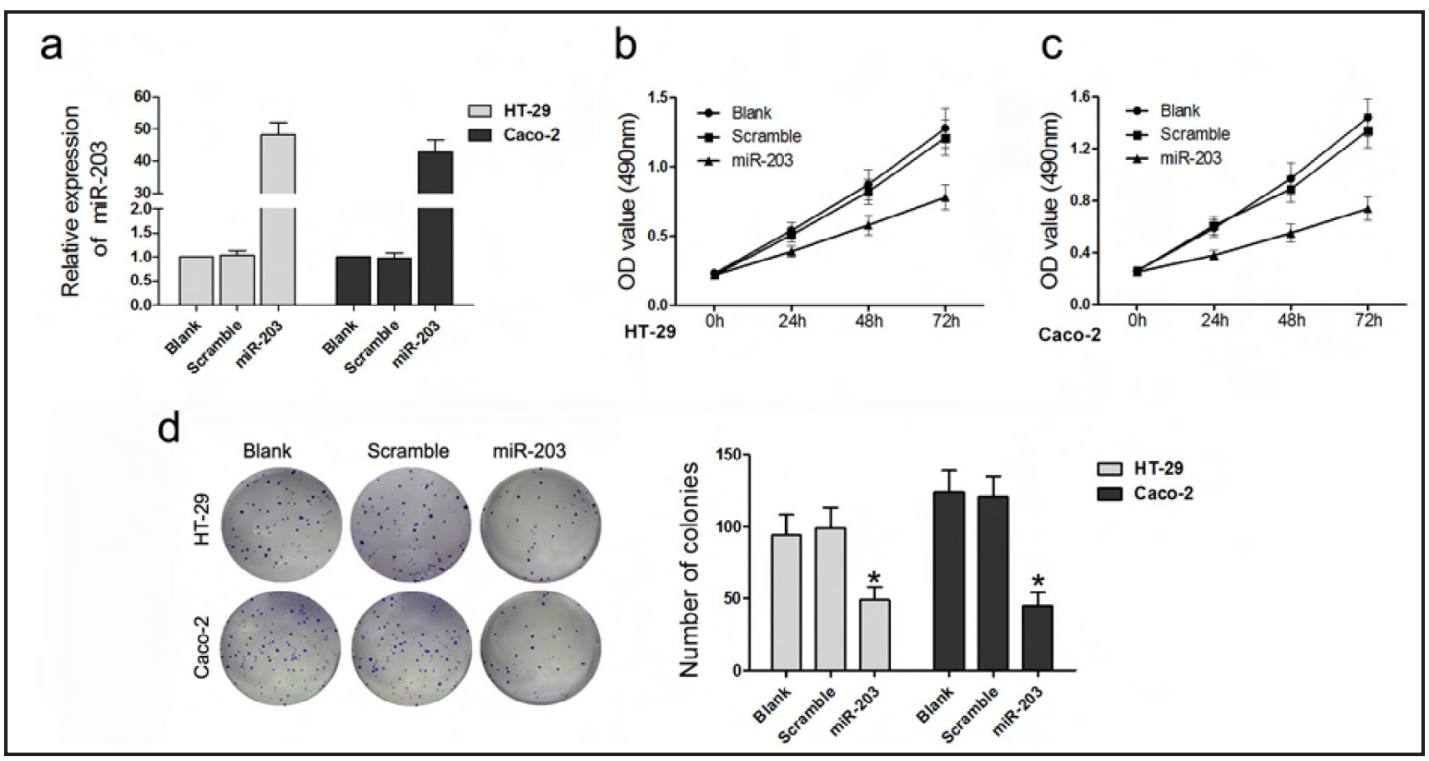

Fig. 3. Upregulation of miR-203 inhibits CRC cell proliferation and colony formation. (a) qRT-PCR was used to examine the expression of miR-203 in HT-29 cells and Caco- 2 cells. MTT assay was used to measure cell proliferation of HT-29 (b) and Caco-2 cell lines (c). Data were shown as the OD value at 490mm. (d) Colony formation assay showed the representative micrographs and quantification of cell colonies. $* P<0.05$, compared with the blank and scramble group. Error bars represent \pm S.E.

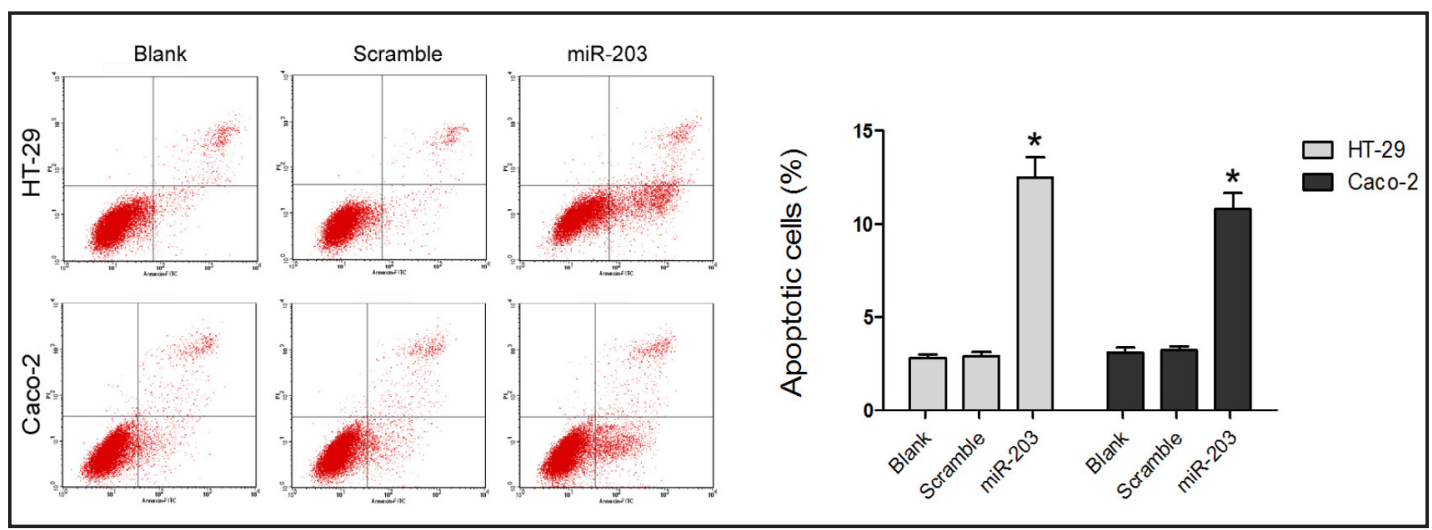

Fig. 4. Upregulation of miR-203 induces CRC cell apoptosis. Flow cytometry was conducted to analyze cell apoptosis of HT-29 and Caco-2 cells. The dot plots indicate the frequency of apoptotic cells. The bars show the summarized data of the dot plots. ${ }^{*} P<0.05$, compared with the blank and scramble group. Error bars represent \pm S.E.

Upregulation of miR-203 inhibits CRC cell proliferation and colony formation

The results showed that miR-203 was increased in HT-29 and Caco-2 cells after the miR-203 transfection (Fig. 3a). By MTT and colony formation assays, we observed that the OD value and colony number of cells with miR-203 transfection were lower than the blank or scramble controls in both cell lines $(\mathrm{P}<0.05$; Fig. $3 b-\mathrm{d})$. The results suggest that miR-203 upregulation inhibits CRC cell proliferation and colony formation.

\section{Upregulation of miR-203 induces CRC cell apoptosis}

Flow cytometry was applied to assess the apoptosis of miR-203 transfected HT-29 and Caco-2 cells. The frequency of the apoptotic cells of the miR-203 group was higher than the blank and scramble control groups ( $\mathrm{P}<0.05$; Fig. 4), suggesting the upregulation of miR-203 induced apoptosis in both HT-29 and Caco- 2 cells.

\section{KARGER}




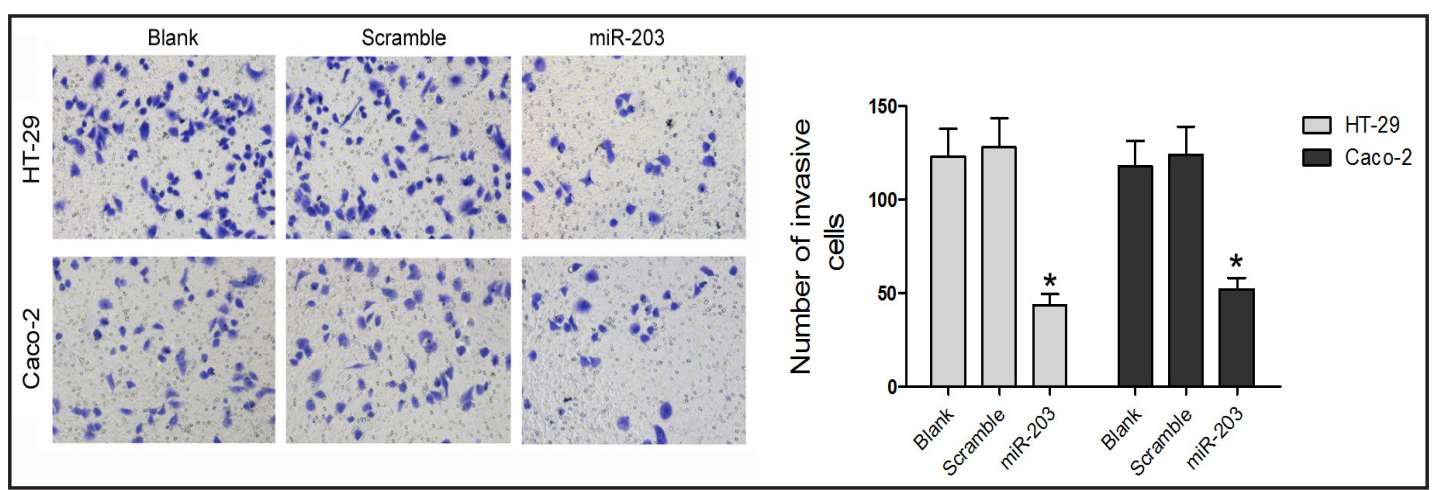

Fig. 5. Upregulation of miR-203 decreases CRC cell invasion. Cell invasion assay was conducted to evaluate the invasive ability of HT-29 and Caco-2 cells. The images show the number of invasive cells. The bars indicate the summarized data of the invading cells in the images. $* P<0.05$, compared with the blank group. Error bars represent \pm S.E.

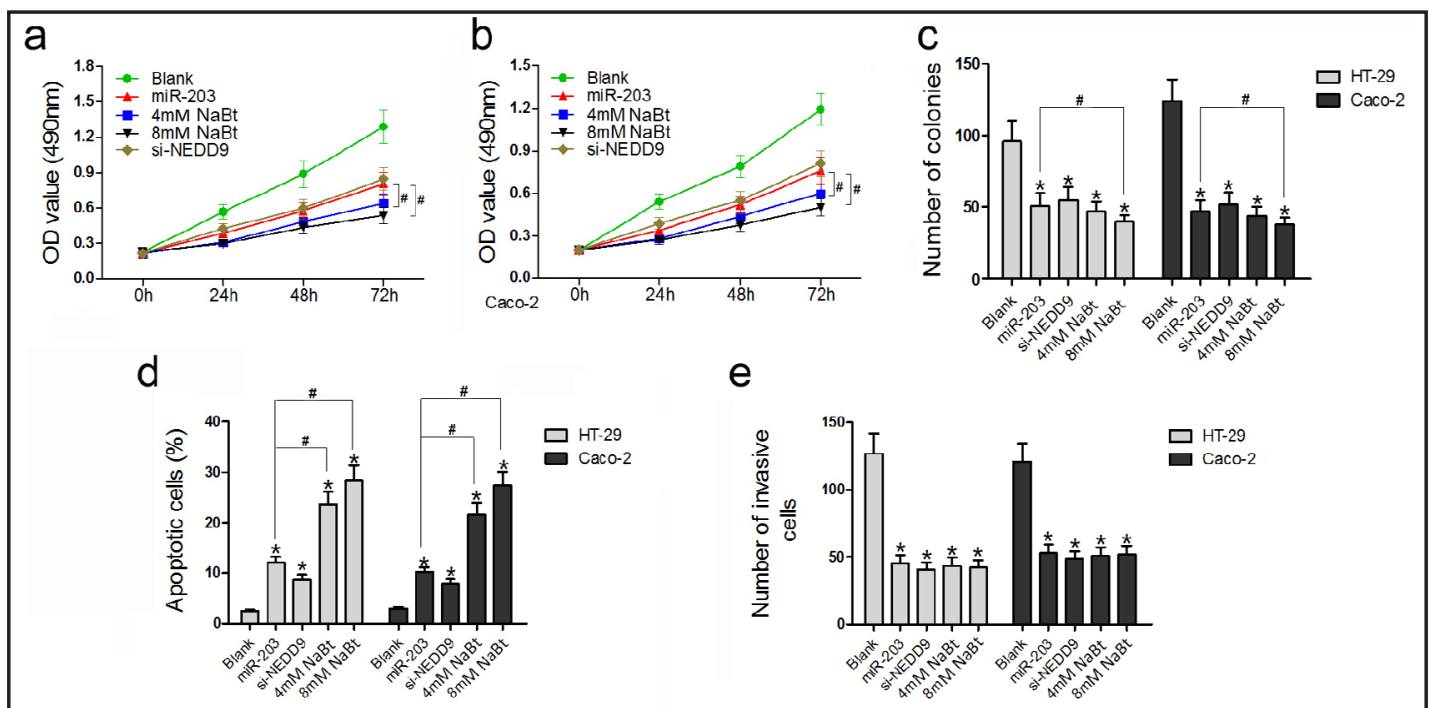

Fig. 6. NaBt presents similar trends in affecting CRC cell proliferation, colony formation, cell apoptosis and invasion with miR-203 upregulation and NEDD9 knockdown. (a-b) MTT assays. (c) Colony formation assays. (d) Flow cytometry. (e) Cell invasion assays. ${ }^{*} P<0.05$, compared with the blank group. $\# P<0.05$, compared with the miR-203 group. Error bars represent \pm S.E.

\section{Upregulation of miR-203 inhibits CRC cell invasion}

Since CRC cells have the invading ability, the effects of miR-203 on CRC cell invasion were examined. Fig. 5 showed that overexpression of miR-203 significantly inhibited HT-29 and Caco-2 cell invasion compared with the control groups $(\mathrm{P}<0.05 ;$ Fig. 5).

NaBt presents similar trends in affecting CRC cell proliferation, colony formation, cell apoptosis and invasion with miR-203 upregulation and NEDD9 knockdown

We observed HT-29 and Caco-2 cells treated with NaBt, transfected with miR-203 or NEDD9 siRNA exhibited a significant decrease in OD value, which indicates that $\mathrm{NaBt}$, miR203 and NEDD9 knockdown have inhibitory effects on CRC cell proliferation $(\mathrm{P}<0.05$; Fig. $6 \mathrm{a}$ and $\mathrm{b}$ ). Meanwhile, the OD value of $\mathrm{NaBt}$ (4or $8 \mathrm{mM}$ ) group was lower than the miR-203 group in HT-29 and Caco-2 cells ( $\mathrm{P}<0.05$; Fig. $6 \mathrm{a}$ and b). Compared with the blank control group, the number of colonies in NaBt, miR-203 or NEDD9 siRNA groups was significantly decreased, indicating the inhibitory role of NaBt, miR-203 or NEDD9 siRNA on the ability of CRC cell colony formation $(\mathrm{P}<0.05$; Fig. $6 \mathrm{c})$. The colony number of $8 \mathrm{mM} \mathrm{NaBt}$ group 


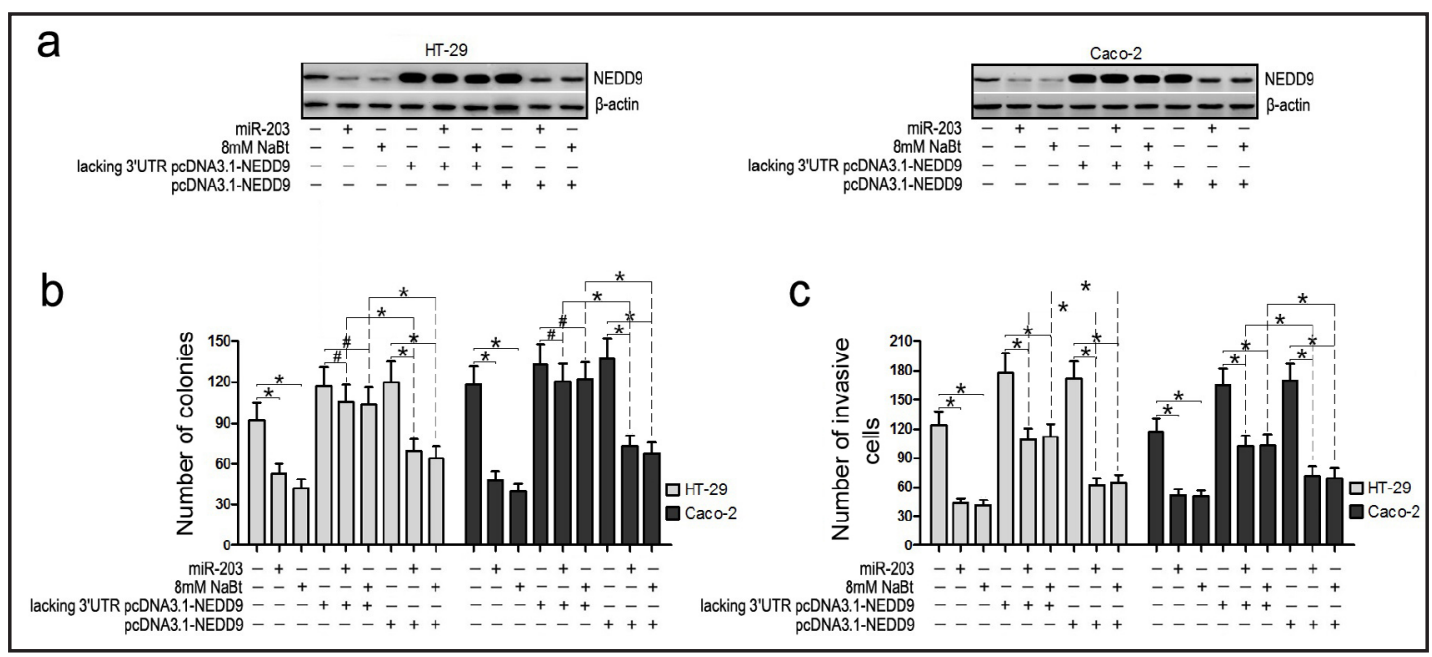

Fig. 7. Overexpression of NEDD9 lacking 3'UTR partially reverses the inhibitory function of miR-203 and NaBt on CRC cells. (a) NEDD9 expression in HT-29 and Caco-2 cells was measured by Western blotting. (b) Colony formation assays. (c) Cell invasion assays. ${ }^{*} P<0.05$, $\# P>0.05$. Error bars represent \pm S.E.

was lower than miR-203 group ( $\mathrm{P}<0.05$; Fig. 6c). Fig. 6d showed that NaBt, miR-203 and NEDD9 siRNA group had a larger percentage of apoptotic cells than the blank control group. Therefore, NaBt, miR-203 and NEDD9 knockdown promote the apoptosis of CRC cells (P < 0.05). Besides, the number of apoptotic cells in $\mathrm{NaBt}$ ( 4 or $8 \mathrm{mM}$ ) group was also higher than miR-203 group ( $\mathrm{P}<0.05$; Fig. 6d). Cell invasion assay demonstrated a significant decrease of invasive cells in NaBt, miR-203 and NEDD9 siRNA groups compared to the blank control group, which validates the inhibitory effects of NaBt, miR-203 and NEDD9 knockdown on CRC cell invasion ( $<<0.05$; Fig. 6e). However, there was no significant difference between miR203 group and NaBt group ( $>$ > 0.05; Fig. 6e). Taken together, NaBt, miR-203 upregulation and NEDD9 knockdown enhances CRC cell apoptosis, inhibits CRC cell proliferation, colony formation and invasion. NaBt tend to have stronger effects than miR-203 on induction of CRC cell apoptosis, inhibition of CRC cell proliferation and colony formation.

Overexpression of NEDD9 lacking 3'UTR partly reverses the inhibitory effects of miR-203 and NaBt on CRC cells

To further validate that miR-203 is directly involved in the regulation of NEDD9 and the miR-203/NEDD9 cascade is one of the mechanisms for NaBt to regulate CRC cells, Western blotting was firstly conducted to analyze the expression of NEDD9 in HT-29 and Caco-2 cells. Comparing with the blank control group, NEDD9 expression was significantly decreased in miR-203 and NaBt group whereas increased when transfected with pcDNA3.1-NEDD9 or lacking 3'UTR pcDNA3.1-NEDD9 (P < 0.05; Fig. 7a). Comparing with pcDNA3.1-NEDD9 group, NEDD9 expression was significantly decreased in the presence of either miR-203 or NaBt cotransfected with pcDNA3.1-NEDD9 (P < 0.05; Fig. 7a). However, we found that NEDD9 expression showed no significant difference in the presence of either miR-203 or NaBt cotransfected with lacking 3'UTR pcDNA3.1-NEDD9 compared to the lacking 3'UTR pcDNA3.1-NEDD9 group ( $\mathrm{P}>0.05$; Fig. 7a). We conclud that NEDD9 expression is not affected by NaBt or miR-203 when HT-29 and Caco-2 cells are transfected with NEDD9 lacking 3'UTR. We subsequently performed the colony formation and cell invasion assays in HT-29 and Caco2 cells. The colony number of HT-29 and Caco- 2 cells transfected with miR-203 or treated with NaBt was significantly decreased whereas increased when transfected with pcDNA3.1NEDD9 or lacking 3'UTR pcDNA3.1-NEDD9 compared with the blank control group (P < 0.05 ; Fig. $7 \mathrm{~b}$ ). Comparing with pcDNA3.1-NEDD9 group, the colony number was significantly decreased in the presence of either miR-203 or NaBt cotransfected with pcDNA3.1-NEDD9 $(\mathrm{P}<0.05$; Fig. 7a). However, compared to lacking 3'UTR pcDNA3.1-NEDD9 group, the 
colony number showed no significant difference in the presence of either miR-203 or NaBt cotransfected with lacking 3'UTR pcDNA3.1-NEDD9 (P >0.05; Fig. 7b). More colony number of CRC cells was observed in the miR-203 and lacking 3'UTR pcDNA3.1-NEDD9 group than the miR-203 and pcDNA3.1-NEDD9 group, similar results could be seen when comparing $\mathrm{NaBt}$ and lacking 3'UTR pcDNA3.1-NEDD9 group with NaBt and pcDNA3.1-NEDD9 group (P $<0.05$; Fig. $7 \mathrm{~b}$ ). These results illustrate that overexpression of NEDD9 lacking 3'UTR could reverse the inhibitory effects of miR-203 and NaBt on CRC cell colony formation. The number of invasive cells of HT-29 and Caco-2 cells transfected with miR-203 or treated with NaBt was significantly decreased whereas increased when transfected with pcDNA3.1-NEDD9 or lacking 3'UTR pcDNA3.1-NEDD9 compared with the blank control group (P < 0.05; Fig. 7c). Comparing with the NEDD9 pcDNA3.1-NEDD9/lacking 3'UTR pcDNA3.1-NEDD9 group, the number of invasive cells was decreased when cotransfected miR-203 with pcDNA3.1-NEDD9/ lacking 3'UTR pcDNA3.1-NEDD9, similar trends could be seen when comparing pcDNA3.1NEDD9/lacking 3'UTR pcDNA3.1-NEDD9 group with NaBt and pcDNA3.1-NEDD9/lacking 3'UTR pcDNA3.1-NEDD9 group ( $<<0.05$; Fig. 7c). The number of invasive cells in the miR203 and lacking 3'UTR pcDNA3.1-NEDD9 group was increased compared to the miR-203 and pcDNA3.1-NEDD9 group, similar results were also observed when comparing NaBt and pcDNA3.1-NEDD9 group with NaBt and lacking 3'UTR pcDNA3.1-NEDD9 group $(\mathrm{P}<0.05$; Fig. 7c). These results indicate that overexpression of NEDD9 lacking 3'UTR partly reverses the inhibitory effects of miR-203 and NaBt on CRC cell invasion. Taken together, we conclude that Overexpression of NEDD9 lacking 3'UTR partly reverses the inhibitory effects of miR203 and $\mathrm{NaBt}$ on CRC cell colony formation and invasion.

\section{Discussion}

It is generally believed that the occurrence and development of CRC is due to multiple factors, among which hereditary and environmental factors are the most important. Intestinal microecology, which is mainly composed of gut microbiota and dietary, is the primary environmental factor. Increasing evidence demonstrates that colonic microbiota plays a significant role in the pathogenesis CRC [23]. Probiotics such as lactobacillus and bifidobacterium are involved in the prevention of CRC through a variety of mechanisms, including inhibiting the colonization of pathogenic bacteria, impairing the carcinogenicity by decreasing the production of or combining with cancerogen, strengthening the immune reaction of the host and producing effective tumor suppressors such as short chain fatty acids (SCFAs) [2-4]. Epidemiological studies show that a diet rich in fiber decreases the incidence and development of colon cancer, supporting the antitumor effects of SCFAs [24].

As a member of SCFAs, NaBt functions as a tumor suppressor factor during the interactions between intestinal microecology and CRC. Numerous studies have revealed that $\mathrm{NaBt}$ inhibits cell proliferation, invasion and migration as well as induces cell apoptosis and differentiation [25-32]. NaBt has been proven to suppress CRC by acting as an HDAC inhibitor and inhibiting the HDAC activity at the transcription level, resulting in the upor down-regulation of specific genes that were crucial in inducing CRC cell cycle arrest or apoptosis. Beyond that, the ability of $\mathrm{NaBt}$ to regulate gene expression was associated with its regulation of miRNA expression in CRC [33-34]. In the present study, we found that $\mathrm{NaBt}$ upregulated miR-203 in HT-29 and Caco- 2 cell lines, and that NaBt presented similar trends in affecting CRC cell proliferation, colony formation, cell apoptosis and invasion with miR203 upregulation. This demonstrates that NaBt could upregulate miR-203 to inhibit HT-29 and Caco-2 cell lines. Our data also showed that the effects of NaBt on CRC cell proliferation, colony formation and apoptosis were superior to the upregulation of miR-203. This may be explained by the proven mechanism that NaBt inhibits CRC by acting as an HDAC inhibitor [33].

miR-203 is a keratinocyte-derived miRNA that promotes epithelial differentiation from proliferative basal progenitors in the dermis by suppressing p63, a member of the p53 family

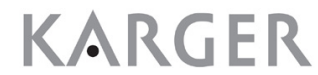


[35-37]. miR-203 is dysregulated in several cancers and it links to the tumor progression. For example, miR-203 is significantly downregulated in prostate cancer and renal cancer, and functions as a tumor suppressor by inhibiting cell proliferation, migration and invasion [38-39]. In studies of colorectal cancer, high levels of miR-203 were detected in CRC [40-42] and increased expression of miR-203 significantly inhibited proliferation, motility, as well as invasion of CRC cells [43], which is consistent with our data. Beyond that, the present study explored the inhibitory effects of miR-203 on CRC cell colony formation, indicating that miR203 had inhibitory effect on the anchorage independent cell growth, which suggested the oncogenic potential of CRC cell.

In previous studies, miR-203 was shown to inhibit proliferation, adhesion, and invasion of prostate cancer cells through directly targeting Rap1A, a member of RAS oncogene family [38] or decreased cell proliferation by targeting Hakai in CRC cells [19]. In our experiments, we performed a bioinformatic analysis to predict the target genes of miR-203 and found that NEDD9 was a target gene of miR-203. NEDD9, also known as HEF1 or Cas-L, is a multidomain scaffolding protein belonging to the Cas family. A number of reports suggest that NEDD9 is a biomarker of invasion, migration, or prognosis in numerous types of cancer including lung cancer, breast cancer, liver cancer, melanoma, and gastric cancer [44-48]. Recently, NEDD9 was found highly expressed in CRC tissues and high NEDD9 expression was correlated with tumor stage and grade, as well as poorer overall survival [49]. Reports pointed out that the elevation of NEDD9 promoted cell proliferation, cell migration and invasion of CRC cells [50-51]. In the present study, the NEDD9 downregulation was shown to exert inhibitory effects on CRC cell proliferation, colony formation and invasion and induce CRC cell apoptosis, which further validates NEDD9 as an oncogene. We also found that miR203 targeted NEDD9. Overexpression of NEDD9 lacking 3'UTR could partially reverse the inhibitory effects of miR-203 on CRC cell colony formation and invasion. These data suggest that miR-203 inhibits CRC cell colony and invasion by binding to the 3'UTR of NEDD9.

In conclusion, our data indicate that NaBt can upregulate miR-203 to inhibit CRC cell proliferation, colony formation and invasion as well as promote CRC cell apoptosis. We also identify NEDD9 as an oncogene and a target gene of miR-203 in CRC cell lines. miR203/NEDD9 cascade may be one of the mechanisms underlying NaBt induces CRC cell suppression. The present study has enriched the mechanisms underlying the process that NaBt exerts anti-tumor effects on CRC cells.

\section{Acknowledgements}

The authors are grateful to all staff at the study center who contributed to this study. This study was supported by the Technical Innovation and Outstanding Talent Foundation of Henan Province (NO. 134200510022), the National Natural Science Foundation of China (NO. 81370494) and Municipal Talent Programs of Zhengzhou (NO.131PLJRC656).

\section{Disclosure Statement}

The authors declare that they have no conflicts of interest

\section{References}

1 Brenner H, Kloor M, Pox CP: Colorectal cancer. Lancet 2014;383:1490-1502.

2 Hirayama K, Baranczewski P, Akerlund JE, Midtvedt T, Möller L, Rafter J: Effects of human intestinal flora on mutagenicity of and DNA adduct formation from food and environmental mutagens. Carcinogenesis 2000;21:2105-2111.

3 Knasmüller S, Steinkellner H, Hirschl AM, Rabot S, Nobis EC, Kassie F: Impact of bacteria in dairy products and of the intestinal microflora on the genotoxic and carcinogenic effects of heterocyclic aromatic amines. Mutat Res 2001;480-481:129-138. 


\section{Cellular Physiology Cell Physiol Biochem 2016;39:1919-1929 and Biochemistry Published online: October 24, 2016 (c) $\begin{aligned} & \text { D 2016 The Author(s). Published by S. Karger AG, Basel } \\ & \text { www.karger.com/cpb }\end{aligned}$}

Han et al.: Sodium Butyrate Inhibits Colorectal Cancer Cell Proliferation

4 Rafter J: Lactic acid bacteria and cancer: mechanistic perspective. Br J Nutr 2002;88:S89-94.

5 Hinnebusch BF, Meng S, Wu JT, Archer SY, Hodin RA: The effects of short-chain fatty acids on human colon cancer cell phenotype are associated with histone hyperacetylation. J Nutr 2002;132:1012-1017.

6 Le Leu RK, Brown IL, Hu Y, Esterman A, Young GP: Suppression of azoxymethane-induced colon cancer development in rats by dietary resistant starch. Cancer Biol Ther 2007;6:1621-1626.

7 Johnstone RW: Histone-deacetylase inhibitors: novel drugs for the treatment of cancer. Nat Rev Drug Discov 2002;1:287-299.

8 Hu S, Dong TS, Dalal SR, Wu F, Bissonnette M, Kwon JH, Chang EB: The microbe-derived short chain fatty acid butyrate targets miRNA-dependent p21 gene expression in human colon cancer. PLoS One 2011;6:e16221.

9 Humphreys KJ, Cobiac L, Le Leu RK, Van der Hoek MB, Michael MZ: Histone deacetylase inhibition in colorectal cancer cells reveals competing roles for members of the oncogenic miR-17-92 cluster. Mol Carcinog 2013;52:459-474.

10 Bartel DP: MicroRNAs: genomics, biogenesis, mechanism, and function. Cell 2004;116:281-297.

11 Schickel R, Boyerinas B, Park SM, Peter ME: MicroRNAs: key players in the immune system, differentiation, tumorigenesis and cell death. Oncogene 2008;27:5959-5974.

12 Slaby O, Svoboda M, Michalek J, Vyzula R: MicroRNAs in colorectal cancer: translation of molecular biology into clinical application. Mol Cancer 2009;8:102.

13 Ventura A, Jacks T: MicroRNAs and cancer: short RNAs go a long way. Cell 2009;136:586-591.

14 Garzon R, Calin GA, Croce CM: MicroRNAs in Cancer. Annu Rev Med 2009;60:167-179.

15 Li HT, Zhang H, Chen Y, Liu XF, Qian J: MiR-423-3p enhances cell growth through inhibition of p21Cip1/ Waf1 in colorectal cancer. Cell Physiol Biochem 2015;37:1044-1054.

16 Zhang W, Zou C, Pan L, Xu Y, Qi W, Ma G, Hou Y, Jiang P: MicroRNA-140-5p inhibits the progression of colorectal cancer by targeting VEGFA. Cell Physiol Biochem 2015;37:1123-1133.

17 Xu K, Liu X, Mao X, Xue L, Wang R, Chen L, Chu X: MicroRNA-149 suppresses colorectal cancer cell migration and invasion by directly targeting forkhead box transcription factor FOXM1. Cell Physiol Biochem 2015;35:499-515.

18 Fang Y, Sun B, Xiang J, Chen Z: MiR-301a promotes colorectal cancer cell growth and invasion by directly targeting SOCS6. Cell Physiol Biochem 2015;35:227-236.

19 Abella V, Valladares M, Rodriguez T, Haz M, Blanco M, Tarrío N, Iglesias P, Aparicio LA, Figueroa A: miR-203 regulates cell proliferation through its influence on Hakai expression. PLoS One 2012;7:e52568.

20 Zhang F, Yang Z, Cao M, Xu Y, Li J, Chen X, Gao Z, Xin J, Zhou S, Zhou Z, Yang Y, Sheng W, Zeng Y: miR-203 suppresses tumor growth and invasion and down-regulates MiR-21 expression through repressing Ran in esophageal cancer. Cancer Lett 2014;342:121-129.

21 Tiwari P, Gupta KP: Modulation of miR-203 and its regulators as a function of time during the development of 7, 12 dimethylbenz [a] anthracene induced mouse skin tumors in presence or absence of the antitumor agents. Toxicol Appl Pharmacol 2014;278:148-158.

22 Tailor D, Hahm ER, Kale RK, Singh SV, Singh RP: Sodium butyrate induces DRP1-mediated mitochondrial fusion and apoptosis in human colorectal cancer cells. Mitochondrion 2014;16:55-64.

23 Scanlan PD, Shanahan F, Clune Y, Collins JK, O'Sullivan GC, O'Riordan M, Holmes E, Wang Y, Marchesi JR: Culture-independent analysis of the gut microbiota in colorectal cancer and polyposis. Environ Microbiol 2008;10:789-798.

24 Trock B, Lanza E, Greenwald P: Dietary fiber, vegetables, and colon cancer: critical review and metaanalyses of the epidemiologic evidence. J Natl Cancer Inst 1990;82:650-661.

25 Lu R, Wang X, Sun DF, Tian XQ Zhao SL, Chen YX, Fang JY: Folic acid and sodium butyrate prevent tumorigenesis in a mouse model of colorectal cancer. Epigenetics 2008;3:330-335.

26 Wang L, Luo HS, Xia H: Sodium butyrate induces human colon carcinoma HT-29 cell apoptosis through a mitochondrial pathway. J Int Med Res 2009;37:803-811.

27 Fu H, Shi YQ, Mo SJ: Effect of short-chain fatty acids on the proliferation and differentiation of the human colonic adenocarcinoma cell line Caco-2. Chin J Dig Dis 2004;5:115-117.

28 Heerdt BG, Houston MA, Augenlicht LH: Short-chain fatty acid-initiated cell cycle arrest and apoptosis of colonic epithelial cells is linked to mitochondrial function. Cell Growth Differ 1997;8:523-532.

29 Krishnan M, Singh AB, Smith JJ, Sharma A, Chen X, Eschrich S, Yeatman TJ, Beauchamp RD, Dhawan P: HDAC inhibitors regulate claudin-1 expression in colon cancer cells through modulation of mRNA stability. Oncogene 2010;29:305-312. 


\section{Cellular Physiology Cell Physiol Biochem 2016;39:1919-1929 and Biochemistry Published online: October 24, 2016 (c) $\begin{aligned} & \text { (c) 2016 The Author(s). Published by S. Karger AG, Basel } \\ & \text { www.karger.com/cpb }\end{aligned}$}

Han et al.: Sodium Butyrate Inhibits Colorectal Cancer Cell Proliferation

30 Archer SY, Johnson J, Kim HJ, Ma Q, Mou H, Daesety V, Meng S, Hodin RA: The histone deacetylase inhibitor butyrate downregulates cyclin B1 gene expression via a p21/WAF-1-dependent mechanism in human colon cancer cells. Am J Physiol Gastrointest Liver Physiol 2005;289:G696-703.

31 Kim YH, Park JW, Lee JY, Kwon TK: Sodium butyrate sensitizes TRAIL-mediated apoptosis by induction of transcription from the DR5 gene promoter through Sp1 sites in colon cancer cells. Carcinogenesis 2004;25:1813-1820.

32 Kobayashi H, Tan EM, Fleming SE: Sodium butyrate inhibits cell growth and stimulates p21WAF1/CIP1 protein in human colonic adenocarcinoma cells independently of p53 status. Nutr Cancer 2003;46:202211.

33 Pajak B, Orzechowski A, Gajkowska B: Molecular basis of sodium butyrate-dependent proapoptotic activity in cancer cells. Adv Med Sci 2007;52:83-88.

34 Blottière HM, Buecher B, Galmiche JP, Cherbut C: Molecular analysis of the effect of short-chain fatty acids on intestinal cell proliferation. Proc Nutr Soc 2003;62:101-106.

35 Sonkoly E, Wei T, Janson PC, Sääf A, Lundeberg L, Tengvall-Linder M, Norstedt G, Alenius H, Homey B, Scheynius A, Ståhle M, Pivarcsi A: MicroRNAs: novel regulators involved in the pathogenesis of psoriasis? PLoS One 2007;2:e610.

36 Yi R, Poy MN, Stoffel M, Fuchs E: A skin microRNA promotes differentiation by repressing 'stemness'. Nature 2008;452:225-229.

37 Sonkoly E, Wei T, Pavez Loriè E, Suzuki H, Kato M, Törmä H, Ståhle M, Pivarcsi A: Protein kinase C-dependent upregulation of miR-203 induces the differentiation of human keratinocytes. J Invest Dermatol 2010;130:124-134.

38 Xiang J, Bian C, Wang H, Huang S, Wu D: miR-203 down-regulates Rap1A and suppresses cell proliferation, adhesion and invasion in prostate cancer. J Exp Clin Cancer Res 2015;34:8.

39 Xu M, Gu M, Zhang K, Zhou J, Wang Z, Da J: miR-203 inhibition of renal cancer cell proliferation, migration and invasion by targeting of FGF2. Diagn Pathol 2015;10:24.

40 Wu X, Li S, Xu X, Wu S, Chen R, Jiang Q, Li Y, Xu Y: The potential value of miR-1 and miR-374b as biomarkers for colorectal cancer. Int J Clin Exp Pathol 2015;8:2840-2851.

41 Schetter AJ, Leung SY, Sohn JJ, Zanetti KA, Bowman ED, Yanaihara N, Yuen ST, Chan TL, Kwong DL, Au GK, Liu CG, Calin GA, Croce CM, Harris CC: MicroRNA expression profiles associated with prognosis and therapeutic outcome in colon adenocarcinoma. JAMA 2008;299:425-436.

42 Bovell LC, Shanmugam C, Putcha BD, Katkoori VR, Zhang B, Bae S, Singh KP, Grizzle WE, Manne U: The prognostic value of microRNAs varies with patient race/ethnicity and stage of colorectal cancer. Clin Cancer Res 2013;19:3955-3965.

43 Li Z, Du L, Dong Z, Yang Y, Zhang X, Wang L, Li J, Zheng G, Qu A, Wang C: miR-203 suppresses ZNF217 upregulation in colorectal cancer and its oncogenicity. PLoS One 2015;10:e0116170.

44 Chang JX, Gao F, Zhao GQ, Zhang GJ: Expression and clinical significance of NEDD9 in lung tissues. Med Oncol 2012;29:2654-2660.

45 Singh MK, Izumchenko E, Klein-Szanto AJ, Egleston BL, Wolfson M, Golemis EA: Enhanced genetic instability and dasatinib sensitivity in mammary tumor cells lacking NEDD9. Cancer Res 2010;70:89078916.

46 Budhu A, Forgues M, Ye QH, Jia HL, He P, Zanetti KA, Kammula US, Chen Y, Qin LX, Tang ZY, Wang XW: Prediction of venous metastases, recurrence, and prognosis in hepatocellular carcinoma based on a unique immune response signature of the liver microenvironment. Cancer Cell 2006;10:99-111.

47 Kim M, Gans JD, Nogueira C, Wang A, Paik JH, Feng B, Brennan C, Hahn WC, Cordon-Cardo C, Wagner SN, Flotte TJ, Duncan LM, Granter SR, Chin L: Comparative oncogenomics identifies NEDD9 as a melanoma metastasis gene. Cell 2006;125:1269-1281.

48 Feng J, Zhao J, Xie H, Yin Y, Luo G, Zhang J, Feng Y, Li Z: Involvement of NEDD9 in the invasion and migration of gastric cancer. Tumour Biol 2015;36:3621-3628.

49 Li P, Zhou H, Zhu X, Ma G, Liu C, Lin B, Mao W: High expression of NEDD9 predicts adverse outcomes of colorectal cancer patients. Int J Clin Exp Pathol 2014;7:2565-2570.

50 Li Y, Bavarva JH, Wang Z, Guo J, Qian C, Thibodeau SN, Golemis EA, Liu W: HEF1, a novel target of Wnt signaling, promotes colonic cell migration and cancer progression. Oncogene 2011;30:2633-2643.

51 Kim SH, Xia D, Kim SW, Holla V, Menter DG, Dubois RN: Human enhancer of filamentation 1 Is a mediator of hypoxia-inducible factor-1alpha-mediated migration in colorectal carcinoma cells. Cancer Res 2010;70:4054-4063. 